\title{
Nucleus accumbens dopamine D2-receptor expressing neurons control behavioral flexibility in a place discrimination task in the IntelliCage
}

\author{
Tom Macpherson, ${ }^{1}$ Makiko Morita, ${ }^{1}$ Yanyan Wang, ${ }^{2}$ Toshikuni Sasaoka, ${ }^{3}$ \\ Akira Sawa, ${ }^{4}$ and Takatoshi Hikida ${ }^{1}$ \\ ${ }^{1}$ Medical Innovation Center, Kyoto University Graduate School of Medicine, Kyoto 606-8507, Japan; ${ }^{2}$ Department of Pharmacology, \\ Beckman Institute, University of Illinois, Urbana, Illinois 61801, USA; ${ }^{3}$ Brain Research Institute, Niigata University, Niigata 951-8585, \\ Japan; ${ }^{4}$ Department of Psychiatry, Johns Hopkins University School of Medicine, Baltimore, Maryland 21205, USA
}

\begin{abstract}
Considerable evidence has demonstrated a critical role for the nucleus accumbens (NAc) in the acquisition and flexibility of behavioral strategies. These processes are guided by the activity of two discrete neuron types, dopamine D1- or D2-receptor expressing medium spiny neurons (D1-/D2-MSNs). Here we used the IntelliCage, an automated group-housing experimental cage apparatus, in combination with a reversible neurotransmission blocking technique to examine the role of NAc D1- and D2-MSNs in the acquisition and reversal learning of a place discrimination task. We demonstrated that NAc D1- and D2MSNs do not mediate the acquisition of the task, but that suppression of activity in D2-MSNs impairs reversal learning and increased perseverative errors. Additionally, global knockout of the dopamine D2L receptor isoform produced a similar behavioral phenotype to D2-MSN-blocked mice. These results suggest that D2L receptors and NAc D2-MSNs act to suppress the influence of previously correct behavioral strategies allowing transfer of behavioral control to new strategies.
\end{abstract}

[Supplemental material is available for this article.]

The ability to learn behavioral strategies resulting in rewarding outcomes, as well as flexibly adapt behavior to match the changing contingencies of our environment, is critical for survival. Indeed, altered reward learning and behavioral flexibility are common features of various major psychiatric disorders, including schizophrenia and drug addiction (Elliott et al. 1995; Cardinal and Everitt 2004; Schoenbaum et al. 2004; Waltz and Gold 2007; Gold et al. 2008).

The recent development of the IntelliCage, an automated group-housing experimental apparatus, has allowed researchers to explore learning processes within a more natural environmental setting. Indeed, early experiments using the IntelliCage demonstrated its value for measuring spontaneous, as well as conditioned, behaviors (Knapska et al. 2006; Onishchenko et al. 2007; Mechan et al. 2009; Võikar et al. 2010). More recently, IntelliCage place discrimination tasks have been used to investigate higher-order cognitive functions in both normal and disease model mice. Acquisition and reversal of place discrimination was found to differ between various commonly used inbred mouse strains (Krackow et al. 2010; Endo et al. 2011), and valproatetreated C57BL/6 mice, used as a model of autism, displayed impairments in place learning associated with perseverative responding (Puscian et al. 2014). However, little is known about the neural circuitry that mediates performance on this task.

The nucleus accumbens (NAc) plays an important role in the acquisition and flexibility of reward and aversive behavioral strategies (Floresco et al. 2009; Macpherson et al. 2014; Hikida et al. 2016). Critical to the ability of the NAc to control reward and aver-

\footnotetext{
Corresponding author: hikida@tk.med.kyoto-u.ac.jp

Article is online at http://www.learnmem.org/cgi/doi/10.1101//m.042507. 116.
}

sive learning are the activity of two types of intermingled output neurons, distinguished by their expression of dopamine receptors and releasable peptides. Dopamine D1-receptor, dynorphin-, and substance P-expressing medium spiny neurons (D1-MSNs), and D2-receptor and enkephalin-expressing medium spiny neurons (D2-MSNs) (Gerfen and Young 1988; Gerfen et al. 1990). Blockade of neurotransmission in NAc D1-MSNs using the selective expression of tetanus toxin impairs acquisition of food or cocaine conditioned place preference (CPP) (Hikida et al. 2010, 2013), as well as visual or response discrimination tasks (Yawata et al. 2012). Whereas, the same method of neurotransmission blocking in NAc D2-MSNs, or intra-NAc infusion of a D2 agonist, does not alter acquisition of visual or response discrimination tasks, but impairs the ability to switch between the two tasks as well as reversal learning within both tasks (Haluk and Floresco 2009; Yawata et al. 2012).

Here, we use a reversible neurotransmission blocking (RNB) technique to investigate the consequences of selectively disrupting neurotransmission in NAc D1- or D2-MSNs on acquisition and serial reversal learning of a place discrimination task in the IntelliCage. Additionally, given previous evidence of the role of dopamine D2 receptors in behavioral flexibility (Kruzich et al. 2006; De Steno and Schmauss 2009; Haluk and Floresco 2009), we decided to explore the functional impact of the deletion of these receptors in the IntelliCage place discrimination task. Specifically, we investigated the consequences of targeted

2016 Macpherson et al. This article is distributed exclusively by Cold Spring Harbor Laboratory Press for the first 12 months after the full-issue publication date (see http://learnmem.cshlp.org/site/misc/terms.xhtml). After 12 months, it is available under a Creative Commons License (AttributionNonCommercial 4.0 International), as described at http://creativecommons. org/licenses/by-nc/4.0/. 
deletion of dopamine D2L receptors, an isoform that predominantly acts postsynaptically (Usiello et al. 2000; Wang et al. 2000).

\section{Results}

\section{Baseline measures of activity and water drinking in RNB and D2L KO mice}

Given that the NAc has been implicated in the control of motor activity (McCullough and Salamone 1992; Swanson and Kalivas 2000) and hypolocomotion in a novel environment has been reported in D2L knockout (KO) mice (Wang et al. 2000; Fetsko et al. 2005), we first examined baseline activity in group-housed NAc D1-MSN blocked (D1-RNB) and D2-MSN blocked (D2-RNB) RNB mice, and D2L KO, heterozygous (HET), and wild-type (WT) mice. We measured visits to the corners and water drinking during a 7 -d period of $24 \mathrm{~h}$ free access to the conditioning chamber corners (Supplemental Fig. S1). No problems were found in the ability to visit conditioning corners or acquire nosepoke responses in any mice. Total visits to the corners were unaffected in D1-RNB, D2-RNB, D2L HET, and D2L KO mice when compared with equivalent WT mice (Supplemental Fig. S1, A; D1-RNB; $F_{(1,15)}=0.18, P=0.68, C ; D 2-R N B ; F_{(1,13)}=0.35, P=0.58, \mathrm{E}$; D2L KO; $\left.F_{(2,28)}=0.51, P=0.95\right)$. Similarly, there was no significant difference in bottle licks in D1-RNB, D2-RNB, D2L HET, and D2L KO mice compared with WT mice (Supplemental Fig. S1, B; $D 1-R N B ; \quad F_{(1,15)}=0.24, \quad P=0.63, \quad \mathrm{D} ; \quad D 2-R N B ; \quad F_{(1,13)}=0.02$, $P=0.89$, F; $\left.D 2 L K O ; F_{(2,28)}=2.37, P=0.11\right)$. Thus, blockade of either NAc D1- or D2-MSNs, or global KO of D2L receptors, does not alter baseline activity or water drinking in group-housed mice.

\section{Acquisition of place discrimination in RNB mice}

We next examined the role of NAc D1- and D2-MSNs in the ability to learn an IntelliCage place discrimination task designed by Endo et al. (2011). Acquisition of place discrimination requires mice to discriminate and shuttle between diagonally facing rewarded but not nonrewarded corners. Both D1-RNB and D2-RNB were able to acquire place discrimination to a similar degree as WT mice, as evidenced by an improvement in the percentage of correct responses over the course of seven daily sessions (Fig. 1A, acquisition stage; D1-RNB, nonsignificant main effect of genotype $F_{(1,15)}=0.27$, $P=0.61$, significant main effect of session $F_{(6,90)}=12.35, P<$ 0.0001 , Fig. 1B, acquisition stage; $D 2-R N B$, nonsignificant main effect of genotype $F_{(1,13)}=0.14, P=0.71$, significant main effect of session $F_{(6,78)}=5.66$, $P<0.0001)$. Thus, NAc D1- or D2-MSNs do not appear to be involved in the acquisition of the current place discrimination task.

\section{Serial reversal learning in RNB mice} Using the same place discrimination task we next explored behavioral flexibility in RNB mice using serial reversals of the response contingency after every seven sessions, so that the previously nonrewarded corners now become rewarded, and vice versa. During the first reversal stage, as with the acquisition stage, all mice demonstrated the ability to learn to discriminate between the rewarded and nonrewarded corners, indicated by an improvement in the percentage of correct responses over the course of severror bars indicating \pm SEM. en sessions (Fig. 1A, Rev 1; D1-RNB, significant main effect of session $F_{(6,90)}=25.50, P<0.0001$, Fig. $1 \mathrm{~B}$, Rev $1 ; D 2-R N B$, significant main effect of session $\left.F_{(6,78)}=11.95, P<0.0001\right)$. However, the percentage of correct responses across the reversal stage as a whole was significantly decreased in D2-RNB (Fig. 1B, Rev 1; significant main effect of genotype $\left.F_{(1,13)}=4.75, P<0.05\right)$, but not D1-RNB mice (Fig. 1A, Rev 1 ; main effect of genotype $F_{(1,15)}=$ $0.09, P=0.77)$ when compared with WT mice.

When analyzed across the three reversal stages, overall performance improved with each consecutive stage in D1-RNB and D2-RNB mice and equivalent WT mice (Fig. 1A, Rev 1-3; $D 1-R N B$, significant main effect of stage $F_{(2,30)}=17.77, P<$ 0.001 , Fig. $1 \mathrm{~B}$, Rev 1-3; D2-RNB, significant main effect of stage $\left.F_{(2,26)}=12.81, P<0.001\right)$. Indeed, impaired performance of reversal learning in D2-RNB mice was restored to the level of WT mice by the final stage (Fig. $1 \mathrm{~B}, \mathrm{Rev} 3$; nonsignificant main effect of genotype $\left.F_{(1,13)}=0.58, P=0.46\right)$.

\section{Perseveration in RNB mice}

During the first reversal, both D1-RNB and D2-RNB and WT mice demonstrated a significant decrease in perseverative errors over the course of seven sessions (Fig. 2A, Rev 1; D1-RNB, significant main effect of session $F_{(6,90)}=51.18, P<0.0001$, Fig. $2 \mathrm{~B}$, Rev 1 ; $D 2-R N B$, significant main effect of session $F_{(6,78)}=29.78, P<$ $0.0001)$. However, over the whole stage, the percentage of perseverative errors was significantly elevated in D2-RNB (Fig. 2B, Rev 1; significant main effect of genotype $\left.F_{(1,13)}=9.11, P<0.01\right)$ but not D1-RNB (Fig. 2A, Rev 1; effect of genotype $F_{(1,15)}=0.14$, $P=0.71)$ mice when compared with WT mice.

Across the three reversal stages, the percentage of perseverative errors decreased with each consecutive stage in all mice (Fig. $2 \mathrm{~A}$, Rev 1-3; D1-RNB, significant main effect of stage $F_{(2,30)}=$ 17.77, $P<0.001$, Fig. 2B, Rev 1-3; D2-RNB, significant main effect of stage $\left.F_{(2,26)}=12.81, P<0.001\right)$. Similar to impairment in correct responding, increased perseverative errors in D2-RNB mice were restored to the level of WT mice by the final stage (Fig. 2B, Rev 3; nonsignificant main effect of genotype $\left.F_{(1,13)}=0.11, P=0.74\right)$.

Finally, we investigated whether perseverative errors and correct responses were predictive of each other. During the reversal stages, the percentage of perseverative errors was significantly negatively correlated with the percentage of correct responses in WT and D1-RNB (Fig. 3A; WT, $r=-0.96 P<0.001, D 1-R N B$,

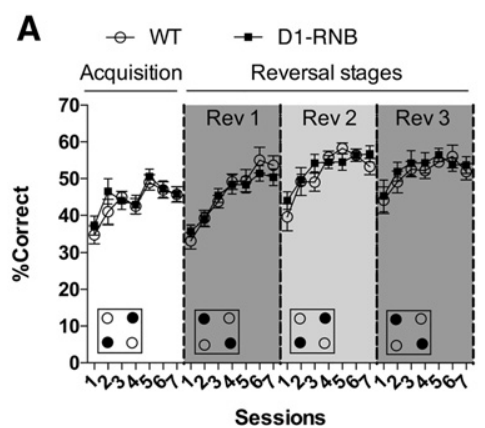

Sessions

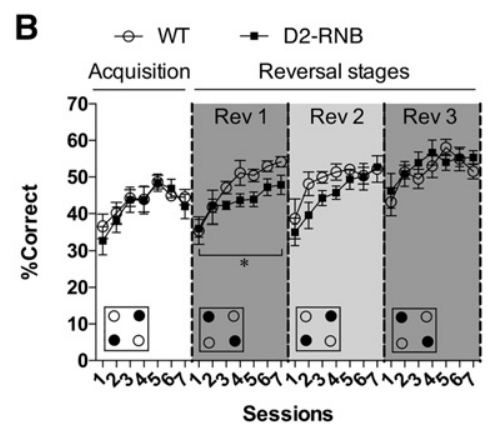

Sessions

Figure 1. Acquisition and serial reversal of an IntelliCage place-learning task in NAc RNB mice. $(A)$ WT $(n=9)$ and NAC D1-RNB $(n=8)$ mice did not significantly differ in acquisition and reversal learning of shuttling responses in the place-learning task. $(B)$ NAc D2-RNB $(n=8)$ mice showed normal acquisition, but impaired reversal learning of the place-learning task when compared with WT $(n=7)$ mice. $\left(^{*}\right) P<$ 0.05 , significant main effect of genotype in the first reversal stage (Rev 1$)$. Decreased percentage of correct responses in D2-RNB mice was restored to the level of WT mice by the third reversal stage (Rev 3 ). Small boxes at the bottom represent an example of the IntelliCage setup for each stage, with filled circles indicating the reward-paired corners and empty circles indicating the non-reward-paired corners. Graph points represent the mean responses for each genotype, with 
A

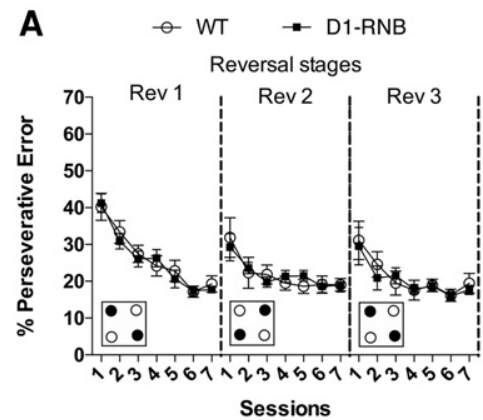

B

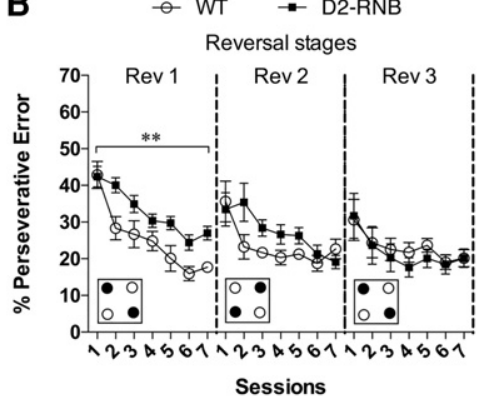

Figure 2. Perseverative errors in NAc D1- and D2-RNB mice. $(A)$ The percentage of perseverative errors during any of the reversal stages did not significantly differ between WT $(n=9)$ and NAc D1-RNB $(n=8)$ mice. $(B)$ The percentage of perseverative errors was significantly higher in NAc D2-RNB $(n=8)$ mice than that in WT $(n=7)$ mice. $\left(^{* *}\right) P<0.01$, significant main effect of genotype in the first reversal stage ( $\operatorname{Rev} 1$ ). Increased perseverative errors in D2-RNB mice were restored to the level of WT mice by the third reversal stage (Rev 3). Small boxes at the bottom represent an example of the IntelliCage setup for each stage, with filled circles indicating the reward-paired corners and empty circles indicating the non-reward-paired corners. Graph points represent the mean responses for each genotype, with error bars indicating \pm SEM.

$r=-0.89 P<0.001$ ) and WT and D2-RNB (Fig. 3B; $W T, r=-0.93$ $P<0.001, D 2-R N B, r=-0.92 P<0.001)$ mice. Thus, the impairment in reversal learning in D2-RNB mice is directly correlated to the elevated perseverative responding at previously correct corners.

\section{Place and reversal learning in D2L KO mice}

Given that NAc D2-MSNs are heavily influenced by dopamine transmission at D2 receptors (Gerfen et al. 1990), we next decided to explore the functional impact of deletion of these receptors. Differential splicing of the $\mathrm{D} 2$ receptor gene creates two isoforms, short (D2S) receptors and long (D2L) receptors, which may act predominantly at the presynapse and postsynapse, respectively (Usiello et al. 2000; Wang et al. 2000). As we were interested in the postsynaptic effect of dopamine transmission on NAc D2-MSNs, we chose to investigate the consequences of deletion of D2L receptors.

As with D1-RNB and D2-RNB mice, D2L HET and KO mice did not significantly differ from WT mice in their ability to acquire the place discrimination task (Fig. 4A, Acquisition stage; nonsignificant main effect of genotype $F_{(2,28)}=2.75, P=0.08$, significant main effect of session $\left.F_{(6,168)}=40.33, P<0.0001\right)$. Similarly, during the first reversal stage, all mice demonstrated an increase in the percentage of correct responses across the course of seven sessions (Fig. 4A, Rev 1; significant main effect of session $F_{(6,168)}=$ $32.35, P<0.0001)$. However, overall performance across the stage
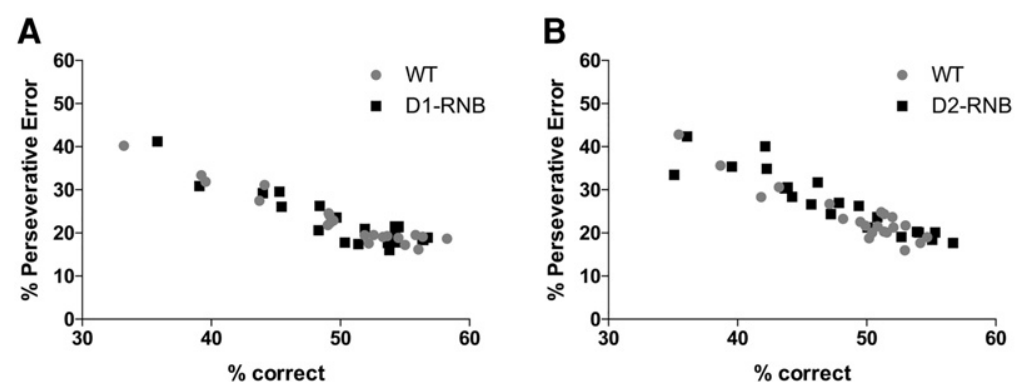

Figure 3. Correlation between the percentage of correct responses and the percentage of perseverative errors during reversal stages in RNB mice. Both D1-RNB $(A)$, D2-RNB $(B)$ and equivalent WT mice showed a significant negative correlation between the percentage of correct responses and the percentage of perseverative errors during the reversal stages.

was revealed to differ between genotypes (Fig. 4A, Rev 1; significant main effect of genotype $\left.F_{(2,28)}=7.62, P<0.01\right)$. Post hoc analysis revealed D2L HET $(P<$ $0.05)$ and $\mathrm{KO}(P<0.01)$ mice had a significantly decreased percentage of correct responses in the stage when compared with WT mice. This was accompanied by a significant difference in the percentage of perseverative errors between genotypes at this stage (Fig. 4B, Rev 1; significant main effect of genotype $\left.F_{(2,28)}=5.30, P<0.05\right)$. Post hoc analysis revealed $D 2 L \mathrm{KO}(P<0.01)$ perseverative errors to be significantly elevated when compared with WT mice, while perseverative errors in HET mice did not reach significance $(P=0.05)$.

Across the three reversal stages, the percentage of correct responses improved with each consecutive stage in all animals (Fig. 4A, Rev 1-3; significant main effect of stage $\left.F_{(2,56)}=27.85, P<0.001\right)$. This corresponded with a reduction in the percentage of perseverative errors at each successive stage in all genotypes (Fig. 4B, Rev 1-3; significant main effect of stage $\left.F_{(2,56)}=34.32, P<0.001\right)$. Additionally, as with D2-RNB mice, impairment in correct responding and elevated perseverative errors in D2L HET and KO mice dissipated by the final stage (Fig. 4A, Rev 3; \% correct, nonsignificant main effect of genotype $F_{(2,28)}=1.01, P=0.38$, Fig. $4 \mathrm{~B}$, Rev $3 ; \%$ perseverative error, nonsignificant main effect of genotype $F_{(2,28)}=0.72, P=$ $0.49)$. Post hoc analysis revealed the percentage of correct responding and perseverative errors in D2L HET and KO to not significantly differ from WT mice (Fig. 4A, Rev 3; \% correct, HET $P=0.35$, KO $P=0.79$, Fig. $4 \mathrm{~B}$, Rev 3 ; \% perseverative error, HET $P=0.48$, KO $P=0.67)$.

Finally, a Pearson's correlation coefficient revealed a significant negative correlation between the percentage of correct responses and the percentage of perseverative errors in all genotypes (Fig. 4C; WT, $r=-0.93, P<0.001$, HET, $r=-0.95$, $P<0.001$, KO, $r=-0.95 . P<0.001)$. Thus, as with D1-RNB and D2-RNB mice, the degree of perseveration at the previously correct corners was directly predictive of the performance on the placelearning task irrespective of genotypes.

\section{Discussion}

Previous evidence indicates that activity in NAc D1-MSNs controls reward learning and addictive behaviors (Macpherson et al. 2014; Nakanishi et al. 2014; Hikida et al. 2016). Indeed, blocking neurotransmission in D1-MSNs of the NAc inhibits acquisition of spatial and response discriminationtasks, and impairs food CPP (Hikida et al. 2010, 2013; Yawata et al. 2012). Similarly, RNB suppression or optogenetic activation of NAc D1-MSNs attenuates or enhances, respectively, cocaine CPP (Hikida et al. 2010, 2013; Lobo et al. 2010). However, in the current study, acquisition of place discrimination in an IntelliCage system was unaffected by neurotransmission blocking in NAc D1- or D2-MSNs. These data suggest a dissociation in the neural circuitry mediating responding in this place 


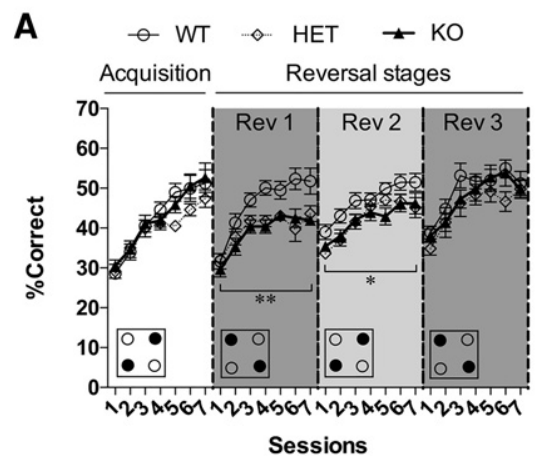

B

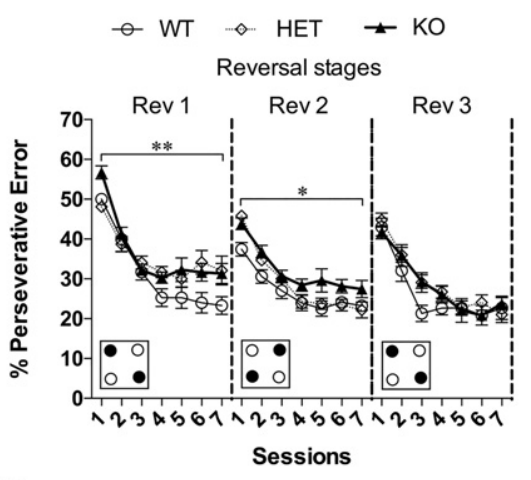

C

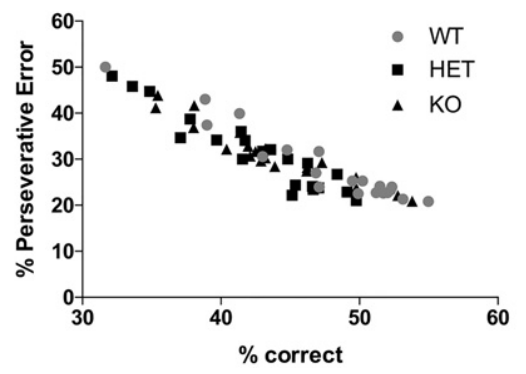

Figure 4. Place-learning in $D 2 L$ KO mice. $(A)$ All genotypes demonstrated normal acquisition of the place-learning task. However, D2L HET $(n=11)$ and KO $(n=11)$ mice were significantly impaired in reversal learning compared with WT mice $(n=9)$. $\left.{ }^{* *}\right) P<0.01 ;\left(^{*}\right) P<0.05$, significant main effect of genotype in the first ( $\operatorname{Rev} 1)$ and second (Rev 2$)$ reversal stages. Decreased percentage of correct responses in HET and KO mice returned to the level of WT mice by the final reversal stage (Rev 3). (B) The percentage of perseverative errors was significantly higher in HET and KO mice than that in WT mice. $\left.{ }^{* *}\right) P<0.01 ;\left({ }^{*}\right) P<0.05$, significant main effect of genotype in the first $(\operatorname{Rev} 1)$ and second $(\operatorname{Rev} 2)$ reversal stages. As with the percentage of correct responses in $A$, the percentage of perseverative errors normalized to WT mice levels by the third reversal stage ( $\operatorname{Rev} 3)$. (C) The percentage of correct responses and the percentage of perseverative errors were significantly negatively correlated in all genotypes. Small boxes at the bottom represent an example of the IntelliCage setup for each stage, with filled circles indicating the reward-paired corners and empty circles indicating the non-reward-paired corners. Graph points represent the mean responses for each genotype, with error bars indicating \pm SEM.

discrimination task with other spatial cue-based reward learning tasks using chocolate as a strong reward, known to affected by RNB of D1-MSNs in the NAc (Yawata et al. 2012). The dorsal striatum has been identified to be critical for the acquisition of goaldirected instrumental tasks (Yin et al. 2005; Balleine et al. 2007;
Featherstone and McDonald 2004a,b). Thus, it is possible that in the current study, acquisition of place discrimination may be mediated by D1- or D2-MSNs within the dorsal striatum.

Alternatively, it is possible that little reward learning is required to perform the current task, leaving it unaffected by neurotransmission blocking of NAc D1- or D2-MSNs. However, we argue that this is likely not the case, as our previous studies have revealed that NAc D1-MSNs are necessary for acquisition of more simple visual discrimination and place conditioning tasks (Hikida et al. 2010; Yawata et al. 2012). A more difficult version of the reward-based place discrimination task, for instance, one that requires a longer sequence of behavioral responses in order to achieve the water reward, may address these possible alternative explanations of our data.

Although acquisition was unaffected, our data revealed transmission blocking in NAc D2- but not D1-MSNs attenuated performance in the place discrimination task following reversal of the reward-paired corners, indicating a deficit in behavioral flexibility. This is congruent with previous evidence from our group demonstrating activity in NAc D2-MSNs to control reversal learning in both visual and response discrimination tasks (Yawata et al. 2012). Similarly, global KO of D2L receptors impaired performance in the reversal stages of the IntelliCage task, consonant with studies demonstrating deletion of D2 receptors to impair reversal learning in odor and texture discrimination tasks (Kruzich et al. 2006; De Steno and Schmauss 2009). Interestingly, the findings from HET mice indicate that even a $50 \%$ reduction in D2L receptors is sufficient to severely disrupt behavioral flexibility.

Increased errors in the reversal task may be explained by perseveration to the previously correct corners, or alternatively by diminished ability to efficiently learn the new behavioral strategy (i.e., repeated responding at the inactive rewarded corner). In order to elucidate the origin of this error, we examined perseverative errors (the percentage of responses at the nonrewarded corners). Our findings revealed that impaired behavioral flexibility in D2-RNB and D2L KO mice was associated with increased perseverance at the previously rewarded corners. This is interesting given that NAc lesions have previously been reported to impair the ability to acquire and maintain a new strategy, but not to alter perseveration of the previously correct strategy (Annett et al. 1989; Floresco et al. 2006). The difference in the findings of our data compared with that of previous studies may be explained by the time point at which perseverative errors were measured. While we report a significant increase in perseverative errors over the course of seven daily sessions of a reversal stage, other groups have used shorter experimental designs in which acquisition or reversal learning are analyzed within a single session (Annett et al. 1989; Floresco et al. 2006). Indeed, in our experiment, differences in correct responses and perseverative errors were largely not seen until after the first session of the reversal stage.

In both $\mathrm{D} 2-\mathrm{RNB}$ and $\mathrm{D} 2 \mathrm{~L} \mathrm{KO}$, mice impaired reversal learning performance and increased perseverative errors began to normalize across each reversal stage until all mice were performing at similar levels by the final stage. These findings indicate that compensatory mechanisms may occur to counteract the absence of D2L receptors or NAc D2-MSN activity. Interestingly, recent evidence has revealed that a population of D1-MSNs in the NAc project to the same neurons in the ventral pallidum as D2-MSNs (Smith et al. 2013; Kupchik et al. 2015). It is possible that this newly discovered D1-MSN pathway may be recruited in the absence of activity in the classic D2-MSN "indirect" pathway.

Given that deletion of D2L receptors produced a similar phenotype to D2-RNB mice, it could be speculated that the loss of D2L receptors may alter the activity of NAc D2-MSNs. Indeed, we suggest that activity in NAc D2-MSNs likely plays an important 
role in inhibiting the competing influence of previously correct strategies over newly learned correct strategies for control of behavior. Interestingly, D2 receptors and striatopallidal transmission have been implicated in the etiology of a number of psychopathologies, including addiction and obesity (Kenny et al. 2013). Indeed, compulsive eating in rats is associated with decreased D2 receptor expression in the striatum, and knockdown of striatal D2 receptors accelerates the emergence of compulsive-like consumption of high calorie chow (Johnson and Kenny 2010). Similarly, pharmacogenetic inhibition of striatopallidal neurons enhances cocaine sensitization, while optogenetic stimulation of striatopallidal neurons or NAc D2-MSNs attenuated cocaine $\mathrm{CPP}$ and compulsive cocaine self-administration, respectively (Lobo et al. 2010; Ferguson et al. 2011; Bock et al. 2013). These studies, alongside the findings from the current study, suggest that D2-MSNs of the dorsal striatum and NAc may provide an efficacious therapeutic target for the treatment of disorders associated with compulsive behaviors. Future research using targeted deletion of NAc D2L receptors could elucidate whether D2L receptors alter activity in D2-MSNs and whether this is sufficient to modulate behavioral flexibility.

\section{Materials and Methods}

\section{Animals}

Male NAc D1-MSN blocked (D1-RNB), and D2-MSN blocked (D2-RNB) RNB mice and wild-type (WT) littermates were generated using TeNT transgenic mice on a C57BL/6 background, in which the expression of transmission-blocking tetanus toxin light chain is driven by the interaction of tetracycline-repressive transcription factor (tTA) and the tetracycline-responsive element, in a doxycycline-off fashion (Yamamoto et al. 2003). A recombinant AAV virus bilaterally delivered into the NAc (anterior $+1.5 \mathrm{~mm}$, lateral + or $-0.8 \mathrm{~mm}$, and ventral $+3.5 \mathrm{~mm}$ ) restricted expression of tTA specifically to Substance P- (D1-MSN) or Enkephalin- (D2-MSN) containing MSNs, creating D1- and D2-RNB mice, respectively (Hikida et al. 2010). Stereotaxic coordinates were histologically verified following completion of the experiment. RNB mice remained off doxycycline throughout the duration of the experiment, resulting in continuous blockade of neurotransmission in NAc D1- or D2-MSNs. D2L KO, HET, and WT mice were generated by mating D2L HET mice, as described previously (Wang et al. 2000). Following weaning and genotyping at 4-wk old, mice were housed in groups of 10-16 in the IntelliCage apparatus. At 8 wk of age all animals were implanted with a subcutaneous microchip and RNB mice underwent viral infusion followed by a 2 -wk recovery/expression period. Mice were maintained on a 12-h light-dark cycle with lights on at 8:00 a.m. and temperature controlled $\left(24 \pm 2{ }^{\circ} \mathrm{C}\right)$, in a humidity of $50 \pm 5 \%$. All animal handling procedures were approved by the animal research committee of Kyoto University Graduate School of Medicine.

\section{IntelliCage}

The IntelliCage (New Behavior AG, Zurich, Switzerland; http:// www.newbehavior.com) is an automated group-housing apparatus allowing experimental testing within the home cage (see for details Galsworthy et al. (2005) and Endo et al. (2011)). The polycarbonate cage $(55 \times 37.5 \times 20.5 \mathrm{~cm})$ is equipped with four operant conditioning chambers $(15 \times 15 \times 21 \mathrm{~cm})$ located in each corner. Each conditioning chamber contains two water drinking bottles and is accessible by a small opening containing a transponder reader antenna that registers the microchip of the entering mouse. Access to each water bottle is controlled by gated nosepoke holes containing infrared beam-break sensors, which can be programmed to open or remain closed upon a nosepoke response. As each mouse was implanted with a unique microchip, corner entry and nosepoke data could be integrated with microchip readings collected by each conditioning corner's antenna, allowing data to be separated by each individual mouse.

\section{Behavioral testing}

\section{Analysis of baseline activity and water drinking}

At 10 wk of age baseline activity and drinking of freely available water were measured in the IntelliCage for $7 \mathrm{~d}$. Analysis was performed on the total amount of corner visits and water bottle licks in order to assess for any preexisting biases in locomotion or water drinking between experimental groups before more behavioral testing occurred.

\section{Place discrimination learning and serial reversal learning}

Following evaluation of baseline activity and water drinking, mice began nosepoke training, during which they had to perform a nosepoke beam-break at the hole in front of the water bottles in any corner in order to gain access for a 5-sec period. During the first $3 \mathrm{~d}$, mice obtained water by nosepoke responses at any time during the $24 \mathrm{~h}$. Subsequently, access to water was restricted to a 3 -h period (9-12 p.m.) also requiring a nosepoke response for a 5 -sec access reward. Following $3 \mathrm{~d}$ of water restriction, mice began behavioral testing for place discrimination acquisition and serial reversal learning using the behavioral assay established by Endo et al. (2011). Mice were required to discriminate between pairs of diagonally facing reward-paired and non-reward-paired corners and perform a shuttling sequence between the reward-paired corners in order to gain access to water for $5 \mathrm{sec}$. Following seven consecutive daily 3-h sessions the reward-paired corners were switched to the previously nonreward paired corners, and vice versa, for another seven consecutive daily 3 -h sessions. This reversal process was conducted three times in total.

\section{Data analysis}

The percentage of correct responses was calculated by dividing the total amount of correct responses by total amount of incorrect responses then multiplying by 100 . As the task demands that mice shuttle between the rewarded corners, a response at the inactive rewarded corner would also be deemed incorrect. Thus, the chance of a random response at one of the corners being correct is $25 \%$. The percentage of perseverative errors was calculated by dividing the non-reward-paired corner responses by the total amount of nosepokes for each session, then multiplying by 100 . Data were analyzed using SPSS software (IBM Corporation, NY, USA) and GraphPad Prism 6.0 software (GraphPad Software, La Jolla, CA, USA) by two-way repeated measure ANOVAs and Bonferroni post hoc comparisons. Correlations were measured using Pearson's correlation coefficients. For graphs, data were averaged across experimental groups and presented as the mean response for each session, including error bars representing \pm SEM.

\section{Competing Interest Statement}

The authors declare that there are no conflicts of interest regarding this article.

\section{Acknowledgments}

We thank N. Otani for technical supports. This work was performed at the Open Innovation Laboratory for Drug Discovery and Development by Takeda and Kyoto University's 'Basic and Clinical Research Project for CNS Drugs' supported in part by Takeda Pharmaceutical Company Ltd. This study was supported by the MEXT/JSPS KAKENHI Grant Numbers 15F15107 (T.M.), 26290029 (T.S.) 23120011, and 15H04275 (T.H.), and grants from the Takeda Science Foundation, the Smoking Science Foundation, and the Daiichi-Sankyo Foundation of Life Sciences (T.H.). In addition, A.S. is supported by the NIH (MH-084018, 
MH-094268 Silvio O. Conte Center, MH-069853, MH-085226, MH-088753, and MH-092443), and Y.W. is supported by a Trust-Private fund.

\section{References}

Annett LE, McGregor A, Robbins TW. 1989. The effects of ibotenic acid lesions of the nucleus accumbens on spatial learning and extinction in the rat. Behav Brain Res 31: 231-242.

Balleine BW, Delgado MR, Hikosaka O. 2007. The role of the dorsal striatum in reward and decision making. J Neurosci 27: 8161-8165.

Bock R, Shin JH, Kaplan AR, Dobi A, Markey E, Kramer PF, Gremel CM, Christensen CH, Adrover MF, Alvarez VA. 2013. Strengthening the accumbal indirect pathway promotes resilience to compulsive cocaine use. Nat Neurosci 16: 632-638.

Cardinal RN, Everitt BJ. 2004. Neural and psychological mechanisms underlying appetitive learning: Links to drug addiction. Curr Opin Neurobiol 14: 156-162.

De Steno DA, Schmauss C. 2009. A role for dopamine D2 receptors in reversal learning. Neuroscience 162: 118-127.

Elliott R, McKenna PJ, Robbins TW, Sahakian BJ. 1995. Neuropsychological evidence for frontostriatal dysfunction in schizophrenia. Psychol Med 25: 619-630.

Endo T, Maekawa F, Võikar V, Haijima A, Uemura Y, Zhang Y, Miyazaki W, Suyama S, Shimazaki K, Wolfer D, et al. 2011. Automated test of behavioral flexibility in mice using a behavioral sequencing task in IntelliCage. Behav Brain Res 221: 172-181.

Featherstone RE, McDonald RJ. 2004a. Dorsal striatum and stimulus-response learning: Lesions of the dorsolateral, but not dorsomedial, striatum impair acquisition of a simple discrimination task. Behav Brain Res 150: 15-23.

Featherstone RE, McDonald RJ. 2004b. Dorsal striatum and stimulus-response learning: lesions of the dorsolateral but not dorsomedial, striatum impair acquisition of a stimulus-response-based instrumental discrimination task, while sparing conditioned place preference learning. Neuroscience 124: 23-31.

Ferguson SM, Eskenazi D, Ishikawa M, Wanat MJ, Phillips PE, Dong Y, Roth BL, Neumaier JF. 2011. Transient neuronal inhibition reveals opposing roles of indirect and direct pathways in sensitization. Nat Neurosci 14: 22-24.

Fetsko LA, Xu R, Wang Y. 2005. Effects of age and dopamine D2L receptor-deficiency on motor and learning functions. Neurobiol Aging 26: $521-530$.

Floresco SB, Ghods-Sharifi S, Vexelman C, Magyar O. 2006. Dissociable roles for the nucleus accumbens core and shell in regulating set shifting. J Neurosci 26: 2449-2457.

Floresco SB, Zhang Y, Enomoto T. 2009. Neural circuits subserving behavioral flexibility and their relevance to schizophrenia. Behav Brain Res 204: 396-409.

Galsworthy MJ, Amrein I, Kuptsov PA, Poletaeva II, Zinn P, Rau A, Vyssotski A, Lipp H-P. 2005. A comparison of wild-caught wood mice and bank voles in the Intellicage: Assessing exploration, daily activity patterns and place learning paradigms. Behav Brain Res 157: 211-217.

Gerfen CR, Young WS. 1988. Distribution of striatonigral and striatopallidal peptidergic neurons in both patch and matrix compartments: An in situ hybridization histochemistry and fluorescent retrograde tracing study. Brain Res 460: 161-167.

Gerfen CR, Engber TM, Mahan LC, Susel Z, Chase TN, Monsma FJ, Sibley DR. 1990. D1 and D2 dopamine receptor-regulated gene expression of striatonigral and striatopallidal neurons. Science 250: 1429-1432.

Gold JM, Waltz JA, Prentice KJ, Morris SE, Heerey EA. 2008. Reward processing in schizophrenia: A deficit in the representation of value. Schizophr Bull 34: 835-847.

Haluk DM, Floresco SB. 2009. Ventral striatal dopamine modulation of different forms of behavioral flexibility. Neuropsychopharmacology 34: 2041-2052.

Hikida T, Kimura K, Wada N, Funabiki K, Nakanishi S. 2010. Distinct roles of synaptic transmission in direct and indirect striatal pathways to reward and aversive behavior. Neuron 66: 896-907.

Hikida T, Yawata S, Yamaguchi T, Danjo T, Sasaoka T, Wang Y, Nakanishi S. 2013. Pathway-specific modulation of nucleus accumbens in reward and aversive behavior via selective transmitter receptors. Proc Natl Acad Sci 110: $342-347$.

Hikida T, Morita M, Macpherson T. 2016. Neural mechanisms of the nucleus accumbens circuit in reward and aversive learning. Neurosci Res, in press. http://dx.doi.org/10.1016/j.neures.2016.01.004.

Johnson PM, Kenny PJ. 2010. Dopamine D2 receptors in addiction-like reward dysfunction and compulsive eating in obese rats. Nat Neurosci 13: $635-641$.
Kenny PJ, Voren G, Johnson PM. 2013. Dopamine D2 receptors and striatopallidal transmission in addiction and obesity. Curr Opin Neurobiol 23: 535-538.

Knapska E, Walasek G, Nikolaev E, Neuhäusser-Wespy F, Lipp H-P, Kaczmarek L, Werka T. 2006. Differential involvement of the central amygdala in appetitive versus aversive learning. Learn Mem 13: $192-200$

Krackow S, Vannoni E, Codita A, Mohammed AH, Cirulli F, Branchi I, Alleva E, Reichelt A, Willuweit A, Voikar V, et al. 2010. Consistent behavioral phenotype differences between inbred mouse strains in the IntelliCage. Genes Brain Behav 9: 722-731.

Kruzich PJ, Mitchell SH, Younkin A, Grandy DK. 2006. Dopamine D2 receptors mediate reversal learning in male C57BL/6J mice. Cogn Affect Behav Neurosci 6: 86-90.

Kupchik YM, Brown RM, Heinsbroek JA, Lobo MK, Schwartz DJ, Kalivas PW. 2015. Coding the direct/indirect pathways by D1 and D2 receptors is not valid for accumbens projections. Nat Neurosci 18: 1230-1232.

Lobo MK, Covington ME III, Chaudhury D, Friedman AK, Sun H, Damez-Werno D, Dietz DM, Zaman S, Koo JW, Kennedy PJ, et al. 2010. Cell type-specific loss of BDNF signaling mimics optogenetic control of cocaine reward. Science 330: 385-390.

Macpherson T, Morita M, Hikida T. 2014. Striatal direct and indirect pathways control decision-making behavior. Front Psychol 5: 1301.

McCullough LD, Salamone JD. 1992. Involvement of nucleus accumbens dopamine in the motor activity induced by periodic food presentation: a microdialysis and behavioral study. Brain Res 592: 29-36.

Mechan AO, Wyss A, Rieger H, Mohajeri MH. 2009. A comparison of learning and memory characteristics of young and middle-aged wild-type mice in the IntelliCage. J Neurosci Methods 180: 43-51.

Nakanishi S, Hikida T, Yawata S. 2014. Distinct dopaminergic control of the direct and indirect pathways in reward-based and avoidance learning behaviors. Neuroscience 282: 49-59.

Onishchenko N, Tamm C, Vahter M, Hokfelt T, Johnson JA, Johnson DA, Ceccatelli S. 2007. Developmental exposure to methylmercury alters learning and induces depression-like behavior in male mice. Toxicol Sci 97: $428-437$.

Puscian A, Leski S, Gorkiewicz T, Meyza K, Lipp H-P, Knapska E. 2014. A novel automated behavioral test battery assessing cognitive rigidity in two genetic mouse models of autism. Front Behav Neurosci 8: 140.

Schoenbaum G, Saddoris MP, Ramus SJ, Shaham Y, Setlow B. 2004. Cocaine-experienced rats exhibit learning deficits in a task sensitive to orbitofrontal cortex lesions. Eur J Neurosci 19: 1997-2002.

Smith RJ, Lobo MK, Spencer S, Kalivas PW. 2013. Cocaine-induced adaptations in D1 and D2 accumbens projection neurons (a dichotomy not necessarily synonymous with direct and indirect pathways). Curr Opin Neurobiol 23: 546-552.

Swanson CJ, Kalivas PW. 2000. Regulation of locomotor activity by metabotropic glutamate receptors in the nucleus accumbens and ventral tegmental area. J Pharmacol Exp Ther 292: 406-414.

Usiello A, Baik JH, Rougé-Pont F, Picetti R, Dierich A, LeMeur M, Piazza PV, Borrelli E. 2000. Distinct functions of the two isoforms of dopamine D2 receptors. Nature 408: 199-203.

Võikar V, Colacicco G, Gruber O, Vannoni E, Lipp H-P, Wolfer DP. 2010. Conditioned response suppression in the IntelliCage: assessment of mouse strain differences and effects of hippocampal and striatal lesions on acquisition and retention of memory. Behav Brain Res 213: 304-312.

Waltz JA, Gold JM. 2007. Probabilistic reversal learning impairments in schizophrenia: Further evidence of orbitofrontal dysfunction. Schizophr Res 93: 296-303.

Wang Y, Xu R, Sasaoka T, Tonegawa S, Kung MP, Sankoorikal EB. 2000. Dopamine D2 long receptor-deficient mice display alterations in striatum-dependent functions. J Neurosci 20: 8305-8314.

Yamamoto M, Wada N, Kitabatake Y, Watanabe D, Anzai M, Yokoyama M, Teranishi Y, Nakanishi S. 2003. Reversible suppression of glutamatergic neurotransmission of cerebellar granule cells in vivo by genetically manipulated expression of tetanus neurotoxin light chain. J Neurosci 23: $6759-6767$.

Yawata S, Yamaguchi T, Danjo T, Hikida T, Nakanishi S. 2012. Pathway-specific control of reward learning and its flexibility via selective dopamine receptors in the nucleus accumbens. Proc Natl Acad Sci 109: 12764-12769.

Yin HH, Ostlund SB, Knowlton BJ, Balleine BW. 2005. The role of the dorsomedial striatum in instrumental conditioning. Eur J Neurosci 22: $513-523$.

Received March 31, 2016; accepted in revised form April 27, 2016. 


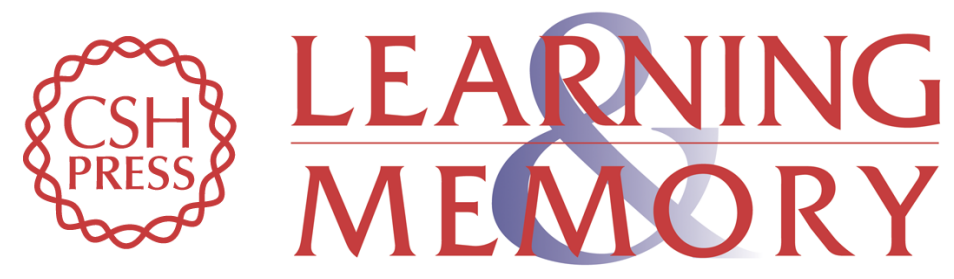

\section{Nucleus accumbens dopamine D2-receptor expressing neurons control behavioral flexibility in a place discrimination task in the IntelliCage}

Tom Macpherson, Makiko Morita, Yanyan Wang, et al.

Learn. Mem. 2016, 23:

Access the most recent version at doi:10.1101//m.042507.116

\section{Supplemental http://learnmem.cshlp.org/content/suppl/2016/06/15/23.7.359.DC1 Material}

References This article cites 43 articles, 10 of which can be accessed free at: http://learnmem.cshlp.org/content/23/7/359.full.html\#ref-list-1

Creative This article is distributed exclusively by Cold Spring Harbor Laboratory Press for the Commons first 12 months after the full-issue publication date (see License http://learnmem.cshlp.org/site/misc/terms.xhtml). After 12 months, it is available under a Creative Commons License (Attribution-NonCommercial 4.0 International), as described at http://creativecommons.org/licenses/by-nc/4.0/.

Email Alerting Receive free email alerts when new articles cite this article - sign up in the box at the Service top right corner of the article or click here. 